\title{
ADAPTAÇÃO DE CADEIRA DE RODAS PARA USUÁRIA COM PARALISIA CEREBRAL NÍVEL 5 NO GMFCS
}

\section{Davi Goulart Martins (UFSC) Ana Veronica Pazmino, Dra. (UFSC)}

\section{INTRODUÇÃO}

Um dos pilares da sustentabilidade é a dimensão social: o desenvolvimento de produtos, serviços, dinâmicas que beneficiem as minorias de forma que promovam a qualidade de vida e a inclusão social.

Envolve atuar em áreas onde não há interesse da economia de mercado e há descaso do poder público.

Este PCC teve uma abordagem social, em que a problemática foi uma demanda da Fundação Catarinense de Educação Especial (FCEE), para o desenvolvimento de projeto para casos específicos de pacientes com paralisia cerebral que necessitavam melhorias em seus equipamentos de locomoção, apontando dois aspectos:

- Os modelos de cadeiras de rodas existentes no mercado nacional apresentam tamanhos e regulagens limitadas onde são feitas pequenas adaptações pelos fabricantes, que dificilmente correspondam às demandas do usuário;

- Os melhores modelos de cadeiras de rodas para pacientes com paralisia cerebral são importados, mas possuem preço pouco acessível em relação aos nacionais.

\section{DESENVOLVIMENTO}

O projeto foi feito para uma jovem de 13 anos, cujo tipo de paralisia cerebral é o nível 5 no GMFCS.

Segundo Palisano (2016):

Nível V GMFCS: Os jovens são transportados em uma cadeira de rodas manual em todos os ambientes. Possuem limitações nas habilidades para manter posturas antigravitacionais da cabeça e do tronco, e o controle dos movimentos dos braços e pernas.

Segundo Cury e Brandão et al.,(2011), os objetivos da adequação postural são:

- Manter alinhamento postural;

- Oferecer suporte corporal e estabilidade;

- Favorecer funções vitais como respiração e digestão;

- Favorecer função cardiorrespiratória;

- Reduzir gasto energético;

- Prevenir alterações secundárias como deformidades e contraturas;
- Melhorar desempenho funcional e participação social;

- Permitir maior independência dos indivíduos;

- Melhorar qualidade de vida.

A partir do conhecimento das necessidades foram feitas pesquisas de tecnologia assistiva, análise de cadeiras de rodas, pesquisa com a usuária e com o terapeuta. Posteriormente o estabelecimento de requisitos de projeto, geração de soluções de apoio de cabeça/tronco, apoio de braço, apoio de pés. Na fase de projeto detalhado foi feita a construção do modelo funcional em tamanho real. A Figura 1 mostra o rendering do produto. E a Figura 20 processo de fabricação.

Figura 1: Rendering

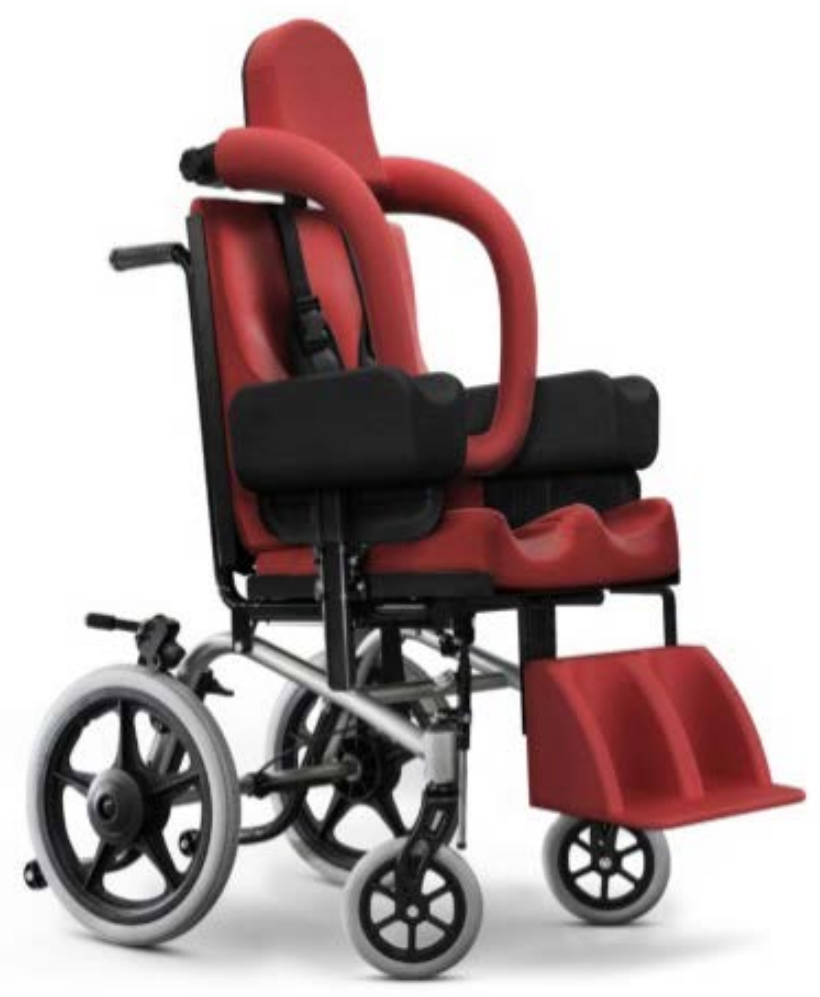

Fonte: Martins (2017) 


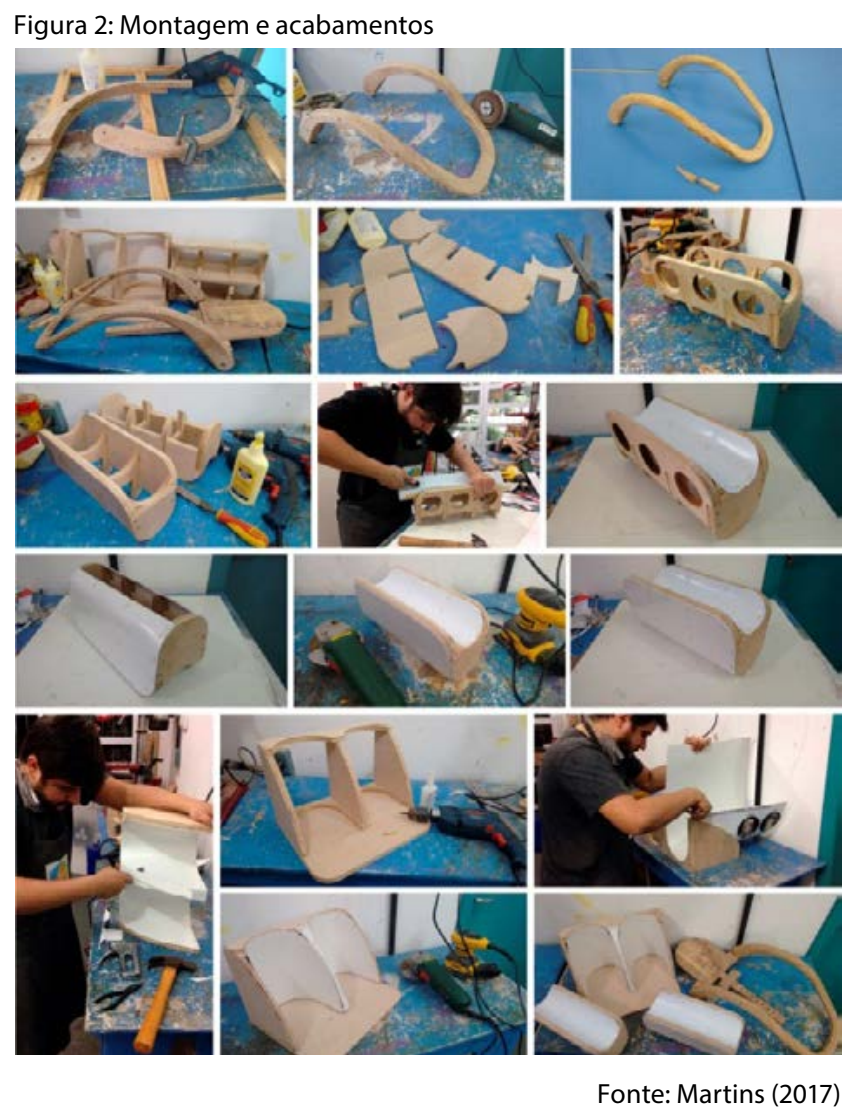

\section{CONCLUSÃO}

O resultado do projeto mostrou que é possível por meio do design desenvolver tecnologias assistivas de baixo custo. E também que existe um campo de atuação para o exercício do design social e design inclusivo.

\section{REFERÊNCIAS}

CURY, V. C. R.; BRANDÃO, M. B. Reabilitação em paralisia cerebral. Rio de Janeiro: MedBook, 2011.

MARTINS, D. G. Projeto de adaptações para cadeira de rodas postural para usuários com paralisia cerebral de nível 5 no GMFCS. PCC Design UFSC, 2017.

PALISANO, R. et al. Gross Motor Function Classification System: GMFCS. [S.I.]: Disponível em: $<$ http://www.canchild.ca>. Acesso em: 22 jun. 2016. 